\title{
Factors of subjective heat stress of urban citizens in contexts of everyday life
}

\author{
Tina Kunz-Plapp ${ }^{1}$, Julia Hackenbruch ${ }^{2}$, and Janus Willem Schipper ${ }^{2}$ \\ ${ }^{1}$ Geophysical Institute, Karlsruhe Institute of Technology, Karlsruhe, Germany \\ ${ }^{2}$ South German Climate Office, Institute of Meteorology and Climate Research, Karlsruhe Institute of Technology, \\ Karlsruhe, Germany \\ Correspondence to: Tina Kunz-Plapp (tina.kunz-plapp@ kit.edu)
}

Received: 7 July 2015 - Published in Nat. Hazards Earth Syst. Sci. Discuss.: 5 August 2015

Revised: 29 January 2016 - Accepted: 29 March 2016 - Published: 19 April 2016

\begin{abstract}
Heat waves and the consequent heat stress of urban populations have a growing relevance in urban risk management and strategies of urban adaptation to climate change. In this context, social science studies on subjective experiencing of heat as stress by urban citizens are a new emerging field. To contribute to the understanding of selfreported subjective heat stress and its major determinants in a daily life perspective, we conducted a questionnaire survey with 323 respondents in Karlsruhe, Germany, after heat waves in July and August 2013. Statistical data analysis showed that subjective heat stress is an issue permeating everyday activities. Subjective heat stress at home was lower than at work and in general. Subjective heat stress in general, at home, and at work was determined by the health impairments experienced during the heat and the feeling of being helplessly exposed to the heat. For subjective heat stress at home, characteristics of the residential building and the built environment additionally played a role. Although the rate of implemented coping measures was rather high, coping measures showed no uniform effect for the subjective heat stress. We conclude that in terms of urban adaptation strategies, further research is needed to understand how various processes of daily social (work) life enable or limit individual coping and that communication strategies are important for building capacities to better cope with future heat waves.
\end{abstract}

\section{Introduction}

Given the increased likelihood of longer, more frequent, and more intense heat waves in Europe (IPCC, 2013), heat waves and the prevention of the consequent heat stress of urban populations have become a growing concern in managing natural hazards impacts on society (WHO and WMO, 2012). The death tolls of the heat waves in Europe in 2003 and 2010 in Moskow, Russia, with estimates of up to 70000 and 20000 fatalities, respectively, (Revich and Shaposhnikov, 2012; Robine et al., 2008) dramatically showed the impacts of extreme heat events on human health. Economic projections expect that with rising temperatures lost labor capacity in peak months of heat stress may double by 2050 (Dunne et al., 2013) and that the average global income may be reduced by $23 \%$ by 2100 (Burke et al., 2015). In particular, urban citizens are likely to suffer heat wave impacts more often in the future due to the urban heat island effect (Beniston et al., 2007; Oke, 1973; Patz et al., 2005; Revi et al., 2014). In Europe, reducing impacts of heat stress thus is among the top issues of urban climate change adaptation strategies (EEA, 2012; Revi et al., 2014).

Heat is a problem individuals experience in their daily lives in a built environment, and they respond to and cope with it in their everyday life settings. To develop effective strategies that help reduce impacts of heat, it is thus necessary to understand how individuals subjectively experience heat as stress in their everyday life and what factors influence and determine it. So far, only a few recent social science studies have investigated the individual, subjective experiencing of heat as stress by using the term subjective heat 
stress (Großmann et al., 2012; Pfaffenbach and Siuda, 2010). Subjective heat stress hereby refers to the individual and selfreported assessment of respondents to what extent they experience high summer temperature as stress. The existing studies have shown that sociodemographic characteristics, health impairments, behavior during the heat, and factors in the urban built environment are associated with higher or lower subjective heat stress. At the same time, however, it is not yet clear to which extent these factors statistically determine subjective heat stress and help explain the inter-individual variance observed.

To close this gap in the current understanding of subjective heat stress of urban citizens, we present results of a questionnaire survey on subjective heat stress (SHS) with 323 respondents conducted in Karlsruhe, Germany. The survey took place in summer 2013 immediately after two heat waves with measured temperatures above $30^{\circ} \mathrm{C}$ and 7 and 6 days, respectively, with heat warnings by the German Weather Service DWD. Our main research aim was to identify what individual, social factors as well as factors of the urban built environment determine the SHS in different contexts of daily life. We therefore investigated to what extent urban citizens experienced heat as stress in their everyday life in general, at home, and at work, and to what extent health impairments, attitude, behavior, housing and urban environment, and sociodemographic factors make a difference to the self-reported heat stress. In this paper, we first outline factors for (subjective) heat stress and heat health impacts as known from different research strands and derive the aim of our study. We then briefly describe the study concept, operationalization, data collection, and analysis in Sect. 3. In Sects. 4 and 5 we present and discuss the results. We finally summarize our conclusions in Sect. 6.

\section{Factors for heat stress}

Factors that contribute to health impacts from heat and to physiological heat stress have been investigated extensively in temperature-related mortality and morbidity studies and in biometeorological studies on human thermal discomfort. More recently, social science perspectives have emerged that focus on subjective heat stress, behavior during heat waves, and on vulnerability to heat.

\subsection{Temperature-related approaches}

Epidemiological studies investigating the relationship between temperature and mortality and morbidity have revealed a widespread pattern of intrinsic, individual, and extrinsic socioeconomic and environmental factors that are associated with increased mortality and morbidity during heat events in addition to high temperatures (Fernandez Milan and Creutzig, 2015). Intrinsic, individual factors for higher mortality found across studies are, in particular, old age and high physiologic susceptibility because of pre-existing health problems or medication use, and also being confined to bed (Conti et al., 2007; Fouillet et al., 2006; Gronlund, 2014; Madrigano et al., 2013; Vandentorren et al., 2006; Zanobetti et al., 2013). Vandentorren et al. (2006) demonstrated additionally the positive effects of individual heat-protective behavior during the heat wave in 2003, e.g., of cooling the body or going outside during cooler times of the day. Extrinsic factors for higher mortality associated with the socioeconomic status are living alone (Fouillet et al., 2006; Uejio et al., 2011), in some cases being female (Borell et al., 2006; D'Ippoliti et al., 2010; Zanobetti et al., 2013), and living in census tracts with a lower socioeconomic status and higher poverty rate (Madrigano et al. 2013; Xu et al., 2013; Zanobetti et al., 2013). Studies in the US observed that ethnicity and linguistic isolation additionally played a role for both higher mortality and heat distress calls (Gronlund, 2014; Uejio et al., 2011). Regarding the urban built environment, increased mortality and hospital admission rates were observed in large cities with high temperatures also during the night (Conti et al., 2007; Grize et al., 2005; Laaidi et al., 2012), in areas with little surrounding green space, and in dense urban structures (Gabriel and Endlicher, 2011; Scherber et al., 2014; Xu et al., 2013). Further studies identified housing conditions, such as living in an area with low property values, in a building with low insulation standard, or having the bedroom in the attic floor, as being associated with higher mortality rates (Smargiassi et al., 2013; Vandentorren et al., 2004, 2006; Xu et al., 2013). Similarly, Harlan et al. (2006) found the combination of dense urban settlement structures and low socioeconomic status to be a factor for vulnerability to heat stress.

To measure the impact of heat on the human body before its consequences become visible in the form of increased morbidity and mortality, biometeorological studies have used indices of thermal discomfort to approach physiological heat stress (Blazejczyk et al., 2012; Jendritzky et al., 2012; Laschewski and Jendritzky, 2002; Staiger et al., 2012). Since individuals spend most of their time indoors and can be exposed to and affected by high temperatures at home or at work, it is necessary to consider also indoor temperatures to understand potential factors for individual heat stress. Several studies therefore explored the outdoor-indoor temperature relationship for different building types and, in some cases, combined meteorological parameters with surveys on heat perception or behavior during heat waves in relation to the indoor temperature (Franck et al., 2013; Semenza et al., 2008; White-Newsome et al., 2012). Their results underpin the small-scale variability of indoor temperatures depending on sensitivities of building materials to outdoor temperatures, characteristics of the building, and its surroundings. Studies for German cities additionally showed that indoor temperatures in the analyzed buildings increased with higher floor level (Franck et al., 2013; Langner et al., 2014). Comparing temperature measurements with survey results on sub- 
jective heat perception during a heat wave in Leipzig, Germany, Franck et al. (2013) found that the evening temperatures measured in the bedroom dominated the heat perception, whereas other parameters, such as urban structure type and green space showed no clear relation to heat perception. In their in-depth study of 29 homes, White-Newsome et al. (2011) showed that heat-protective behavior was significantly associated with increasing indoor temperatures, and that residents in high-rise buildings and impervious areas showed a higher rate of behavior changes to adjust to the heat.

\subsection{Factors of heat stress in a social science perspective}

A recently growing number of social science studies have explored subjective heat stress and vulnerability to heat using more or less explicitly - various theoretical frameworks and concepts of the natural hazards and climate change research community. Some of them focused on the risk perception and the response to heat warnings of vulnerable groups such as the elderly (Abrahamson et al., 2009; Hansen et al., 2011; Sampson et al., 2013; Sheridan, 2007) and their social networks (Wolf et al., 2010). Others tried to understand the social dimensions of subjective heat stress and behavior during heat (Großmann et al., 2012) or the social production of heat wave impacts (Klinenberg, 2002). The studies employed qualitative or quantitative research designs and because of their timing, they differ as well regarding the temporal relation to heat experience. In some of them, data collection took place during a heat wave (Großmann et al., 2012; Klinenberg, 2002; Sheridan, 2007), in others in the summer season without pronounced heat (Abrahamson et al., 2009; WhiteNewsome et al., 2011), in late spring (Pfaffenbach and Siuda, 2010), or during winter (Kalkstein and Sheridan, 2007).

Despite these conceptual and methodical differences, the common explicit or implicit understanding underlying the research activities is that heat and subjective heat stress are problems that unfold in the context of everyday social life and that a number of individual and social characteristics interacting with health and urban spatial structures affect subjective heat stress and coping behavior. In contrast to the previously mentioned biometeorological approach using thermal discomfort indices (Harlan et al., 2006; Langner et al., 2014), subjective heat stress (SHS) refers here to the subjective and individual experiencing of heat as stress that is measured with the statements expressed by individual study participants.

This definition and measurement has been used in previous empirical studies on SHS among residents of the German cities Leipzig (Großmann et al., 2012), Aachen (Pfaffenbach and Siuda, 2010), and Nuremberg (Wittenberg et al., 2012). These clearly indicated that SHS in everyday life is not solely an issue at home and in the residential environment, but also at work. As the most common expression of SHS at work, the studies found a decreased ability to con- centrate due to the heat (Großmann et al., 2012; Pfaffenbach and Siuda, 2010). Similarly, Sampson et al. (2013) pointed to the negative effect of the heat on the energy level and the heat's negative effect to function normally also in daily activities. Other impairments and health-related problems reported by study participants in the context of heat included circulatory complaints, but also headaches, disturbed sleep, exhaustion, and respiratory diseases (Pfaffenbach and Siuda, 2010; Wittenberg et al., 2012). Pfaffenbach and Siuda (2010) found higher SHS rates among respondents with a chronic respiratory or cardiovascular disease. Furthermore, the studies mentioned found significant differences in SHS according to elements of the urban spatial structure (building type and inhabited level in the building, settlement density, and surrounding green space) that correspond to the results of heat discomfort studies outlined above.

Regarding sociodemographic characteristics that make a difference to the intensity of SHS, results of previous studies diverged in particular for elderly persons reporting higher SHS levels than the younger respondents (Pfaffenbach and Siuda, 2010) versus elderly persons reporting lower SHS levels than younger persons (Großmann et al., 2012). Studies among elderly citizens in the UK (Abrahamson et al., 2009; Wolf et al., 2010), the US (Sampson et al., 2013; Sheridan, 2007), and Australia (Hansen et al., 2011) suggested that they did not perceive themselves as vulnerable to heat just because of their chronological age in years. Moreover, as Großmann et al. (2012) found that retired respondents more often changed their daily routines during the heat than the younger and economically active ones, they raised the question as to whether and how the elderly might balance their higher susceptibility to heat with higher coping capacity through their freedom from the constraints of working life.

Studies in several countries showed that people employed various measures during hot-weather periods to cope with the heat (Abrahamson et al., 2009; Kalkstein and Sheridan, 2007; Sampson et al., 2013; Sheridan, 2007). The measures reported throughout the studies can be categorized into three types: changes in routines (for example, drinking more fluids) and changes of daily routines themselves (for example, shifting activities to other parts of the day, seeking cooler places). The third group is the use of available technical or structural measures to modify the indoor environment (ventilation, shading, fans, and primarily in the studies in the US, air conditioning). The observed implementation rate of the various measures to adjust and cope with the heat, however, was rather variable. It ranged from a third of respondents (Pfaffenbach and Siuda, 2010), a half of respondents (Kalkstein and Sheridan, 2007; Sheridan, 2007), to two-thirds of respondents (Großmann et al., 2012). At the same time, beliefs and attitudes also turned out to be relevant in the context of behavior during heat. A few studies (Kalkstein and Sheridan, 2007; Wolf et al., 2010) referred to respondents' reasoning that hot weather is normal during summer and to respondents' narratives that behavior changes in summer are 
just "common sense" (Kalkstein and Sheridan, 2007). Additionally, Wittenberg et al. (2012) observed that respondents perceived persistent heat as a problem one is helplessly exposed to, indicating only a moderate attitude that heat stress is a problem one can actively cope with.

In sum, the outlined results from previous surveys suggest that SHS is an issue relevant in different contexts of daily life. Second, they underline that various sociodemographic characteristics, health and behavior factors, and factors related to the built environment help explain why individuals experience and report more or less SHS. These results, however, were obtained in bivariate analyses and comparisons. The previous studies thus limit conclusions across the factors regarding their effects on SHS, and they limit conclusions on what factors play a major or minor role as determinants for SHS in different contexts of daily life. Additionally, the question is still open as to what proportion of the observed variability in SHS they actually explain. Furthermore, as for some of the mentioned studies the data collection took place without preceding pronounced hot-weather periods, the actual weather conditions and the fact that respondents had to rely on their memories of heat experience might have influenced their responses (Abrahamson et al., 2009).

\section{Methods}

A questionnaire survey was conducted in August 2013 in Karlsruhe, Germany, to identify the determinants of SHS of urban citizens in a multivariate perspective. The general aim of our empirical study was to identify what individual and social factors, and factors of the urban built environment determine the SHS in different contexts of daily life during a heat wave. Our first main research question therefore was to explore to what extent urban citizens experienced heat in various typical daily situations as stress, how their health was affected by the heat, and what measures they implemented to cope with it. Urban citizens experience heat at home, or at work outdoors, or in buildings surrounded by urban structures with small-scale variability of temperatures. Our second main research question therefore was how health, coping attitude, and behavior during the heat wave, age, and other sociodemographic variables on the one hand, and spatial structures and elements of the urban built environment on the other hand, are associated with SHS.

\subsection{Concept of the study}

The study concept based on previous studies (Großmann et al., 2012; Wittenberg et al., 2012) approached SHS as a problem individuals experience and respond to in their everyday life settings in an urban environment. SHS was operationalized as subjective heat stress in general, at home, and at work as the three key dependent variables. SHS was included for 12 additional typical daily activities to account for the vari- ety of everyday life contexts in which people are exposed to heat (see Table 1). For all of them, SHS was measured using the following question in an expressed-preferences approach. "During a hot weather period, to what extent do you experience heat as stress (... in general/at home/at work/etc.)?"

To analyze what makes a difference to subjective heat stress and to identify the main determinants of SHS in general, at home, and at work, the study concept adopted and combined individual, social, behavioral, and environmental factors associated with SHS from previous explorative studies (Großmann et al. 2012; Wittenberg et al., 2012). Adjusting the heuristic framework for vulnerability assessment of Birkmann et al. (2013) to subjective heat stress in everyday life, these factors are related to the exposure to heat in a daily life context, the susceptibility of individuals, and their ability to cope with the heat. The study concept therefore included the factors health, coping attitude, and behavior during the heat, building elements and spatial structures in the urban built environment, and finally a number of sociodemographic characteristics (Table 1). Characteristics of the type of work and work place were also addressed.

Health impairments referring to symptoms suffered during heat, subjective health status, and the negative coping attitude, i.e., the feeling of being helpless against the heat, were adopted from Wittenberg et al. (2012). The measures to cope with the heat referred to changed behavior in response to the heat that can be performed immediately in the "here and now" (Birkmann et al., 2013, p. 193). We hereby used the terms coping behavior and coping measures to distinguish them from long-term adaptation measures to prepare for more future heat waves on an individual or institutional level, such as investments in heat protection and thermal insulation of buildings, urban planning, organization of work processes, and economic production (Ginski et al., 2013). The coping measures were derived from public information material on behavior during heat and from previous research, in particular from the studies by Großmann et al. (2012) and Abrahamson et al. (2009). The elements of the urban built environment covered housing conditions and urban spatial structures tested in previous studies in German cities (Großmann et al., 2012; Pfaffenbach and Siuda, 2010; Wittenberg et al., 2012). We included also heat protection and thermal insulation of buildings that help keep indoor temperature at an acceptable level and opportunities to relax outside and recover from the heat during the cooler times of the day without leaving home. This study concept was translated into a questionnaire with 28 questions that combined standardized questions with Likert scales, with ordinally and categorically coded answers (Table 1).

\subsection{Study area}

Karlsruhe, a city with approximately 300000 inhabitants, is located in the Rhine Valley in southwest Germany. It belongs to the warmest regions in Germany. Until 5 July 2015, Karl- 
Table 1. Variables and scores included in the data analysis.

\begin{tabular}{|c|c|c|c|c|}
\hline Variables & & Scale & $N$ & Results \\
\hline $\begin{array}{l}\text { Subjective heat stress } \\
\text { (dependent variables) }\end{array}$ & $\begin{array}{l}\text { in general } \\
\text { at home } \\
\text { at work }\end{array}$ & 1 (not at all) to 9 (very strong) & $\begin{array}{l}319 \\
317 \\
255\end{array}$ & Fig. 3 \\
\hline $\begin{array}{l}\text { Subjective heat stress in } 12 \text { additional typical } \\
\text { daily activities }\end{array}$ & $\begin{array}{l}\text { at home during daytime } \\
\text { at home sleeping at night } \\
\text { at work } \\
\text { on one's way (to work, school, ...) } \\
\text { while doing housework } \\
\text { while doing shopping } \\
\text { during leisure and sports activities } \\
\text { in public transport } \\
\text { in the car } \\
\text { outside: in parks, gardens, pools } \\
\text { in your residential quarter } \\
\text { in the city center }\end{array}$ & $\begin{array}{l}1 \text { (not at all) to } 5 \text { (very strong), } \\
\text { does not apply to me }\end{array}$ & 323 (each) & Fig. 4 \\
\hline \multicolumn{5}{|l|}{ Independent variables } \\
\hline Negative coping attitude & $\begin{array}{l}\text { agreement to the statement "one is helplessly subjected } \\
\text { to the persistent heat" }\end{array}$ & $\begin{array}{l}1 \text { (no agreement at all) to } 5 \text { (full agree- } \\
\text { ment) }\end{array}$ & 319 & \\
\hline Frequency of health impairments experienced & $\begin{array}{l}\text { feel tired } \\
\text { sick feeling } \\
\text { concentration problems } \\
\text { excessive sweating } \\
\text { headaches } \\
\text { circulation problems } \\
\text { sleep disorders } \\
\text { worsening of existing diseases } \\
\text { annoyance by mosquitoes }\end{array}$ & $\begin{array}{l}1 \text { (not all) } \\
2 \text { (seldom) } \\
3 \text { (from time to time) } \\
4 \text { (often) }\end{array}$ & 306 to 318 & Fig. 5 \\
\hline Health impairment score & $\begin{array}{l}\text { sum of frequency of health impairments divided by the } \\
\text { total number of health impairments given that at least } 8 \\
\text { of the } 9 \text { health impairments listed have valid answers }\end{array}$ & $1-4$ & 311 & \\
\hline Subjective health status & $\begin{array}{l}\text { very good, good, satisfactory, impaired, strongly im- } \\
\text { paired }\end{array}$ & 1 (very good) to 5 (strongly impaired) & & \\
\hline Coping measures & $\begin{array}{l}\text { drink plenty } \\
\text { light meals } \\
\text { light clothing } \\
\text { cool body } \\
\text { avoid direct sun } \\
\text { shift work or activities to other times of the day } \\
\text { seek cooler places } \\
\text { avoid exertion } \\
\text { make breaks and slow down } \\
\text { air and shade rooms } \\
\text { use air conditioning } \\
\text { use a fan }\end{array}$ & $\begin{array}{l}\text { implemented, } \\
\text { not implemented, would have liked to } \\
\text { implement if I had had the possibility }\end{array}$ & 307 to 321 & Fig. 6 \\
\hline
\end{tabular}

sruhe held the temperature record for Germany of $40.2^{\circ} \mathrm{C}$ measured during the European heat wave in August $2003^{1}$. As climate model simulations project a warming over Germany in the future (Wagner et al., 2013), the city of Karlsruhe is expected to experience more heat waves. In the city's strategy to adapt to climate change, preventing future heat wave impacts through public health measures, information and communication, and various urban planning measures is of high priority (Stadt Karlsruhe, 2013). Karlsruhe thus provides a suitable setting for a study on SHS.

In 2013, all summer months June, July, and August at the Rheinstetten weather station of the German Weather Service (DWD) just south of Karlsruhe had a positive temperature anomaly compared to the climatological reference pe-

${ }^{1}$ On 5 July 2015, a new official German temperature record of $40.3^{\circ} \mathrm{C}$ was measured at the DWD weather station Kitzingen. riod 1961 to 1990 . In July, 11 hot days with a maximum temperature of $30^{\circ} \mathrm{C}$ or more were measured between 16 and 27 July, with only 1 day below $30^{\circ} \mathrm{C}$ in between (see Fig. 1). This period was followed by 4 hot days in the first 6 days of August with a maximum temperature of $36.8^{\circ} \mathrm{C}$ (German Weather Service, 2014; Mühr, 2014). During these 3 weeks, heat warnings for 6 and 7 consecutive days had been issued by the DWD (see Fig. 1). As there is no standard definition of heat waves (Fischer and Schär, 2010; Lissner et al., 2012; Robinson, 2001; Tinz et al., 2008), we use the term heat wave in our study if heat warnings by the DWD were issued during 3 or more consecutive days. The DWD heat warnings are based on the perceived temperature (PT, Staiger et al., 2012), with warnings of great heat stress with $+32 \leq \mathrm{PT}<38^{\circ} \mathrm{C}$ and of extreme heat stress with PT $>38^{\circ} \mathrm{C}$. The weather conditions were therefore appropriate to study the subjective ex- 
Table 1. Continued.

\begin{tabular}{|c|c|c|c|c|}
\hline Variables & & Scale & $N$ & Results \\
\hline Heat loading of residential district & $\begin{array}{l}\text { residential district assigned to four heat loading } \\
\text { categories* }\end{array}$ & 1 (lowest) to 4 (highest) & 323 & Fig. 2b, Table 5 \\
\hline House type & $\begin{array}{l}\text { one or two-family home, multiple dwelling unit, apart- } \\
\text { ment tower }\end{array}$ & categories & 319 & Table 5 \\
\hline \multirow[t]{2}{*}{ Floor level } & ground level, lower, middle and upper levels, attic & 1 (ground level) to 5 (attic) & 323 & Table 5 \\
\hline & use of multiple floors & yes/no & 323 & Table 5 \\
\hline Heat protection elements (score) & $\begin{array}{l}\text { number of } 3 \text { elements available: } \\
\text { - window shutters } \\
\text { - roller shutters or sun blinds mounted outside the } \\
\text { windows } \\
\text { - air conditioning }\end{array}$ & 0 to 3 elements & 308 & Table 5 \\
\hline Outdoor recreational elements (score) & $\begin{array}{l}\text { number of } 3 \text { elements available: } \\
\text { - balcony or patio } \\
\text { - backyard usable for leisure activities } \\
\text { - garden }\end{array}$ & 0 to 3 elements & 306 & Table 5 \\
\hline Known insulation elements (score) & $\begin{array}{l}\text { number of } 6 \text { available thermal insulation elements } \\
\text { known: } \\
\text { - insulation of the attic } \\
\text { - insulation of exterior walls } \\
\text { - insulated glazing } \\
\text { - green façade } \\
\text { - thick walls typical for buildings before } 1920-1930 \\
\text { - energetic refurbishment in the last } 10 \text { years }\end{array}$ & 0 to 6 elements & 323 & Table 5 \\
\hline Distance to public garden & walking distance to public garden & $\begin{array}{l}1 \text { to } 5 \mathrm{~min} \\
>5 \mathrm{~min}\end{array}$ & 322 & Table 5 \\
\hline Type of work & $\begin{array}{l}\text { My type of work is mainly } \\
\text { - physically demanding } \\
\text { - mentally challenging } \\
\text { - sitting } \\
\text { - standing and walking } \\
\text { - in a fixed and strict daily work schedule } \\
\text { - with warm work safety clothes } \\
\text { - with business dress code }\end{array}$ & yes/no & 252 to 254 & \\
\hline Working environment & $\begin{array}{l}\text { I work mainly } \\
\text { - indoors } \\
\text { - outdoors } \\
\text { - in an air-conditioned environment } \\
\text { - with several colleagues in one office } \\
\text { - from home } \\
\text { - in a particularly warm rooms }\end{array}$ & yes/no & 253 & \\
\hline Sociodemographic variables & $\begin{array}{l}\text { gender } \\
\text { age } \\
\text { living conditions } \\
\text { occupational status }\end{array}$ & categories & 307 to 322 & Table 3 \\
\hline
\end{tabular}

* Residential districts were assigned to heat loading categories based on Bach et al. (2013) and Nachbarschaftsverband Karlsruhe (2013).

periencing of heat as stress. As the Rheinstetten DWD station is not located directly within an urban area, it can be assumed that the temperatures in parts of the city of Karlsruhe were even higher due to the urban heat island effect (Oke, 1973).

\subsection{Data collection and sample}

The survey took place from 9 August until 25 September 2013 immediately after the two heat waves. Data were collected with an online version of the questionnaire that was available on the web page of the South German Climate Office at KIT and that was advertised in the local and social media. Parallel to the online survey, the senior citizens' office of the City of Karlsruhe sent a paper-pencil version of the questionnaire to groups of senior citizens.
In total, 323 respondents living in Karlsruhe participated in the survey, 249 of them online and 74 using the paperpencil questionnaire. 159 of the respondents were female, 158 male. The age of the respondents ranged from 17 to 94 years. Compared to the Karlsruhe population, the sample was somewhat younger, and the proportion of respondents with an academic degree higher. The respondents represent almost all districts of Karlsruhe (see Fig. 2a). Corresponding to the high education level, most of the economically active respondents worked in mentally challenging jobs $(89.4 \%)$, mainly sitting $(85.8 \%$ ) indoors $(95.3 \%)$. Only $6.3 \%$ carried out physically demanding jobs and $3.6 \%$ worked outside. In sum, data collection resulted in a random sample suitable to explore relevant potential determinants of subjective heat stress in general and at home. However, the possibility of an- 


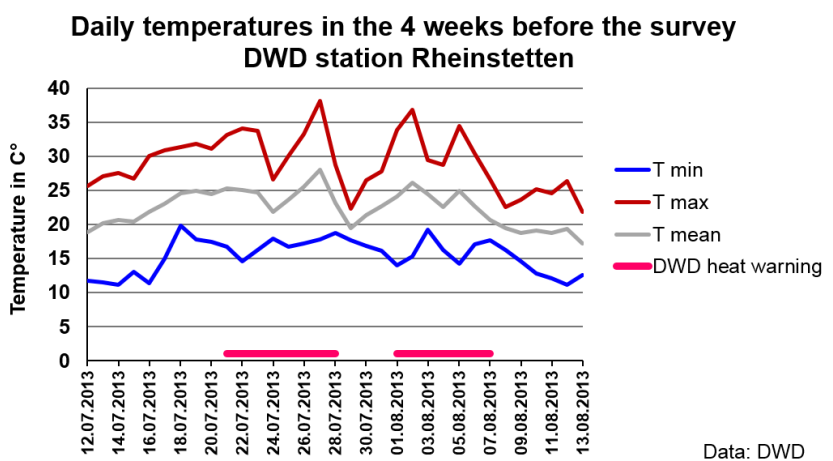

Figure 1. Daily temperatures in Karlsruhe (German Weather Service DWD station Rheinstetten) and days with heat warnings issued by the DWD for Karlsruhe.

alyzing SHS at work is limited because of too little response spread in the characteristics of work type and work place.

\subsection{Data analysis}

Data were analyzed using the program IBM SPSS version 21. First, a descriptive univariate analysis was carried out to explore respondents' SHS in different contexts of daily life, health impairments experienced during heat, their coping attitude, and what measures they used to cope with the heat. In order to understand what makes a difference to low or high SHS in general, at home, and at work, in the next step bivariate correlations and significant differences were tested with variables representing health, sociodemographic characteristics, coping measures, and elements of the spatial built environment. As the three dependent variables of the study, SHS in general, at home, and at work, and also a number of other variables were either not normally distributed or coded on an ordinal level, Spearman's rank correlation coefficients and nonparametric statistical tests were applied.

Finally, three multiple regressions for SHS in general, SHS at home, and SHS at work as dependent variables were performed to identify their main statistic determinants. Those variables referring to health, beliefs, coping measures, sociodemographic variables, and the built environment were entered into the regression models as independent variables that yielded significant results in bivariate analysis and that were plausible given the empirical evidence gained in other studies. The resulting three regression models for SHS in general, at home, and at work showed a good model fit with Durbin Watson values of 1.99, 2.03, and 1.99, respectively. To avoid collinearity, the independent variables had been accepted only if they fulfilled the criteria of a tolerance measure $>0.25$ and a variance inflation factor, $\mathrm{VIF}<5$. Observed tolerance values of $>0.5$ and $\mathrm{VIF}<2$ were the case for all independent variables.

The analysis of SHS at work considered only the economically active respondents $(54.5 \%)$ and the students/trainees
$(21.7 \%)$. Students were included based on the assumption that in the perspective of everyday life experience, the students' and trainees' time and performance requirements in the course of the day correspond to requirements of working life independently of earning an income with their work.

A number of variables first required transformation into scores to finally test them as determinants of SHS (see also Table 1). The health impairments score was developed according to the summated score by Wittenberg et al. (2012) as a measure for the overall health impact during heat for each respondent. We refined their calculation and related the summated frequency of health impairments reported to the total number of health impairments with valid answers. Thermal insulation of buildings and heat protection help keep indoor temperature at home acceptable, and having a balcony or a garden provides opportunities to relax and recover from the heat during the cooler times of the day without leaving home. Our intention was to test the effects of having these possibilities at home for SHS and not primarily the effect of single elements as analyzed in previous studies (Großmann et al., 2012; Pfaffenbach and Siuda, 2010; Wittenberg et al., 2012). The scores for the heat protection, outdoor recreation, and insulation elements therefore each counted the number of elements available in the respondents' residence.

Regarding the residential district of the respondents, the 27 city districts of Karlsruhe were classified into four categories (see Fig. 2b). These categories correspond to settlement density and heat loading as modeled for Karlsruhe based on an urban climate model (Nachbarschaftsverband Karlsruhe, 2013) and on a combined approach using weather stations and remote sensing data (Bach et al., 2013). In the presented study, the two districts in the city center represent the districts with the highest settlement density and highest heat loading. The adjacent four urban districts (south, southwest, east, and west of the city center) represent the category with dense urban settlement and high heat loading. Eleven districts with urban and suburban characteristics form the third category, corresponding to a moderate heat loading. Ten suburban districts that are either located out of town or close to adjacent forests correspond to the category with the lowest heat loading.

\section{Results}

In this section we first show how the respondents experienced the heat as subjective stress in contexts of daily life, what health impairments they felt, and how they coped with the heat. Then we present the results on factors associated with SHS from bivariate and finally from multivariate data analysis. 

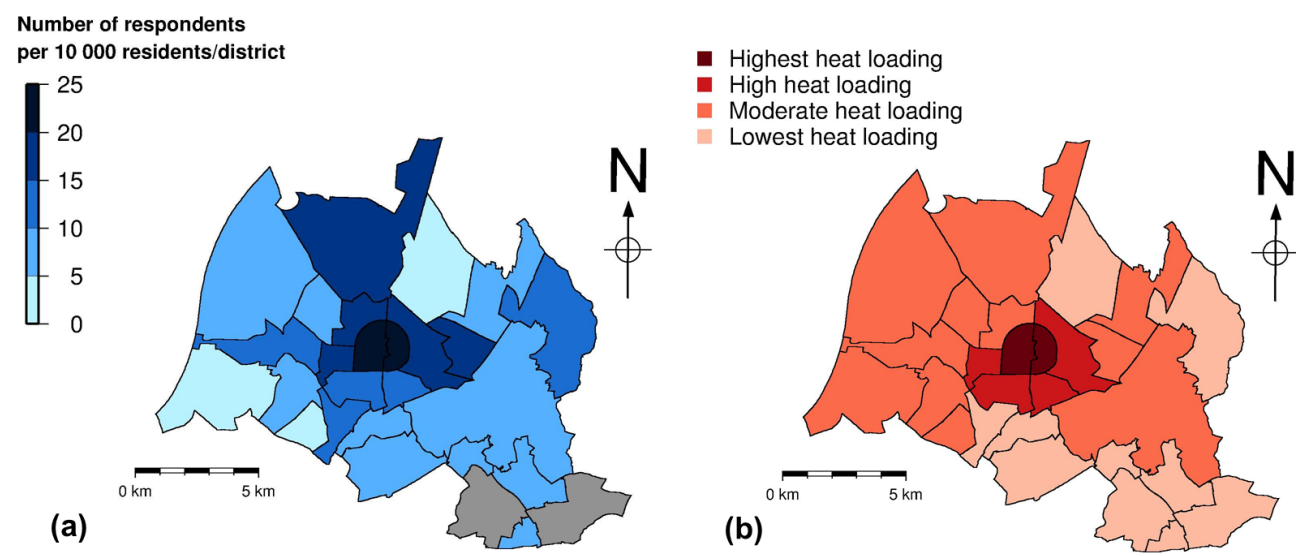

Figure 2. (a) Number of respondents in districts of Karlsruhe per 10000 inhabitants/district. (b) Category of heat loading assigned to the 27 districts of Karlsruhe. The gray color in the figure (a) indicates that there was no participation from this district in the study.

During a hot weather period, to what extent do you experience heat as stress on a scale from 1 (not at all) to 9 (very strong)?

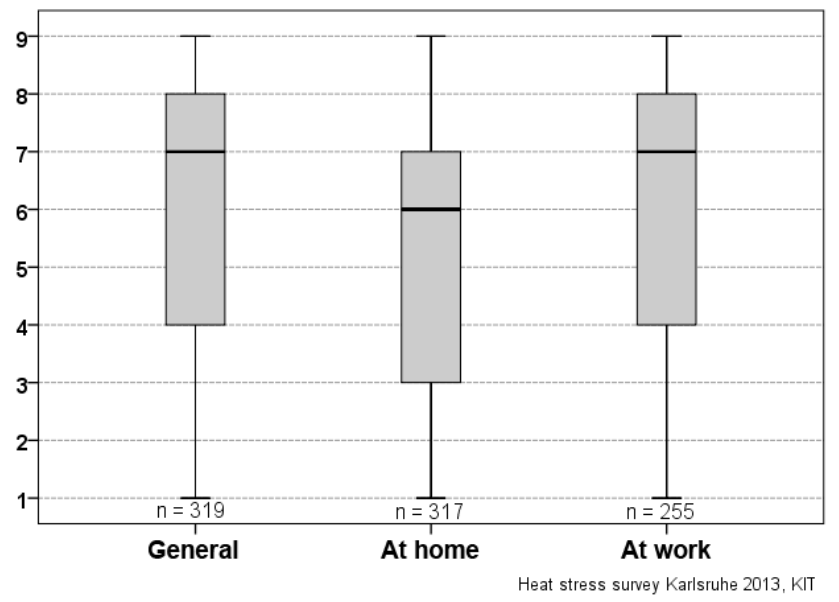

Figure 3. Box plots for subjective heat stress experienced in general, at home, and at work. Only economically active respondents and students/trainees answered the question on heat stress at work.

\subsection{Subjective heat stress, health impairments, and coping with the heat}

The majority of the 323 respondents experienced heat as stress in general, at home, and at work to a rather high extent (Fig. 3). At the same time, the box plots indicate a high individual variability for all of the three SHS variables. Wilcoxon signed-rank tests, however, showed that the SHS at home was significantly lower than the overall general SHS $(z=-4.036, p=0.000)$ and the SHS at work $(z=-2.529$, $p=0.011)$.

Figure 4 displays how respondents experienced heat as stress in 12 typical situations and activities in daily life. More than half of the respondents reported strong or very strong heat stress in public transport, in the city center, and almost

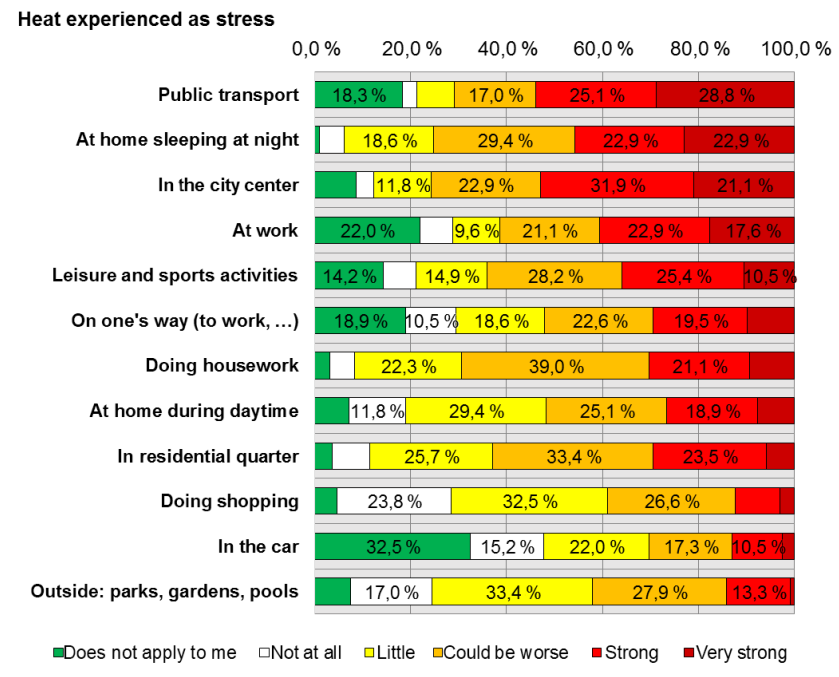

Figure 4. Subjective heat stress experienced by respondents in typical daily activities. Exact numbers for percentages below $10 \%$ are not indicated in the figure.

half of them at home while sleeping at night, and at work. The lowest percentages of heat experienced as stress were reported for being outside in gardens, parks, or pools/lakes, while doing shopping, and while being in the car. For the two latter this can be explained by the fact that most cars and shops or shopping centers are equipped with air conditioning. The responses shown in Fig. 4 also reveal that due to individually different daily routines and life styles, the activities or situations in which heat is experienced did not apply equally to all respondents.

The majority of respondents reported either a very good $(29.4 \%)$ or good $(43.3 \%)$ subjective health status. Respondents aged 65 years and older significantly more often expressed an impaired or strongly impaired state of health than the younger ones, $\chi^{2}(24, n=319)=128.66, p=0.000$. 
Type and frequency of health impairments from heat

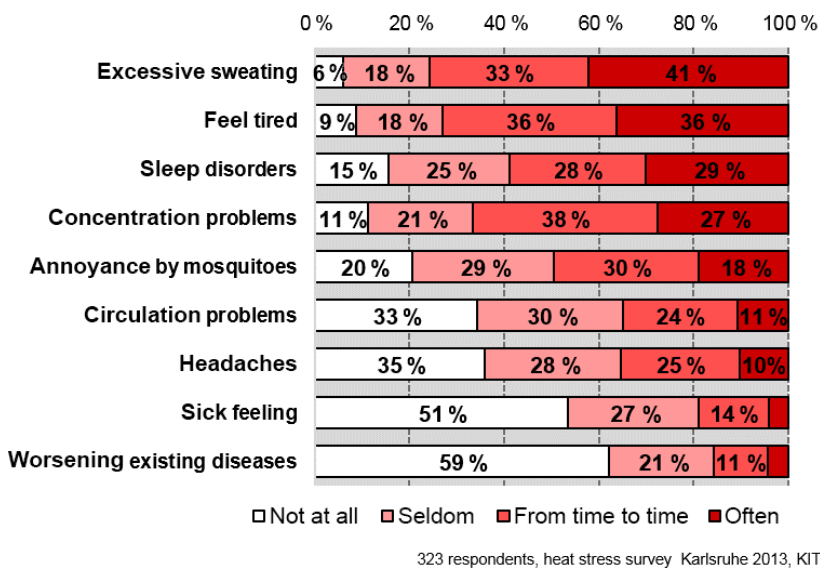

Figure 5. Type and frequency of health impairments from heat reported by respondents. Exact numbers for percentages below $5 \%$ are not indicated in the figure.

Respondents most often reported excessive sweating, feeling tired, sleep disturbances, and concentration problems from the heat (see Fig. 5). Number and frequency of health impairments suffered during the heat was summarized in the health impairments score. The score mean of 2.40 (standard deviation $-\mathrm{SD}=0.60$, score range 1 to 4) indicates that the majority of respondents reported a modest overall rate of health impairments. Respondents with a lower, impaired, or strongly impaired subjective health status reported a higher frequency of worsening of existing diseases $\left(\chi^{2}=111.34, p=0.000\right)$, circulatory problems $\left(\chi^{2}=66.66, p=0.000\right)$, headaches $\left(\chi^{2}=26.96\right.$, $p=0.008)$, and feeling sick $\left(\chi^{2}=25.11, p=0.014\right)$. Elderly persons above 65 years more often reported worsening of existing diseases $\left(\chi^{2}=35.5960, p=0.000\right)$ and having circulatory problems $\left(\chi^{2}=25.49, p=0.013\right)$, but less often having concentration problems $\left(\chi^{2}=43.80, p=0.000\right.$; chisquare tests with 12 degrees of freedom in each case, $n=305$ to 314 ).

The agreement among the respondents to the negative coping attitude, i.e., their being subjected to the heat without being able to do anything against it, was rather high (mean $=3.36, \mathrm{SD}=1.10$ on a scale from 1 to 5 ). Despite this, the majority of them implemented measures to cope with the heat. As can be seen in Fig. 6, almost all participants employed basic behavioral measures that focused on physical well-being during the heat and that could be easily integrated into the daily routine, such as drinking plenty of fluids, wearing light clothes, and eating lighter meals. Among the other behavioral measures that imply changes or alternations in daily routines and thus may require certain flexibility, were avoiding the direct sun, cooling the body, and avoiding exertion or exercise; these were implemented most by the respondents. To a lesser extent, the respondents sought

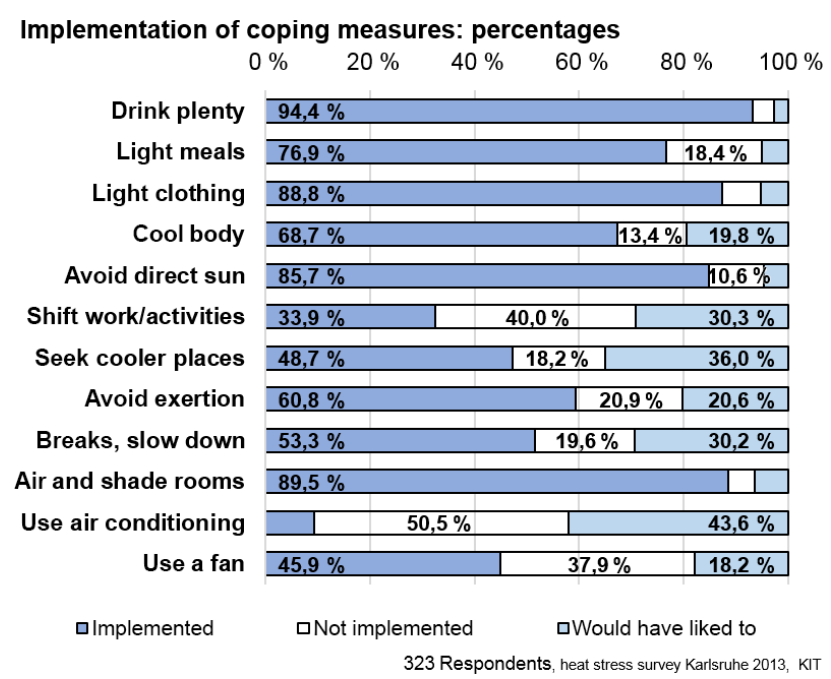

Figure 6. Implementation of coping measures: percentages of respondents. Exact numbers for percentages below $10 \%$ are not indicated in the figure.

cooler places, allowed themselves breaks, and slowed down or shifted work or activities to other (cooler) times of the day. At the same time, approximately up to a third of all respondents would have employed the three latter measures if they had had the possibility to do so. Out of the structural and technical measures to keep the indoor temperature at a tolerable level, almost all respondents used ventilation and shading of their rooms. Fans and in particular air conditioning $(9.8 \%)$ were used less frequently. However, with $43.6 \%$, a reasonable percentage of respondents would have switched on the air conditioning if they had had the possibility to do so.

Female respondents more frequently changed over to lighter meals $\left(\chi^{2}=7.37, p=0.007\right)$ and lighter clothing $\left(\chi^{2}=3.89, p=0.049\right)$ and more often avoided exertion or exercise $\left(\chi^{2}=4.77, p=0.029\right)$. Male respondents more often used air conditioning $\left(\chi^{2}=6.32, p=0.012\right.$; $\mathrm{d} f=1$ in each case, $N=301$ to 316 ). Regarding age, in particular the respondents aged 65 years and older shifted their activities more often to other times of the day $\left(\chi^{2}=41.605, p=0.000\right)$ or allowed breaks and slowing down $\left(\chi^{2}=55.88, p=0.000\right)$. They also more often sought cooler places to evade the heat $\left(\chi^{2}=26.89, p=0.000\right)$, and more often avoided direct sun and exertion $\left(\chi^{2}=11.75\right.$, $p=0.019, \chi^{2}=31.83, p=0.000$ respectively; $\mathrm{d} f=4$ in each case, $n=307$ to 318 ).

\subsection{What makes a difference to subjective heat stress?}

The correlation coefficients (Spearman's rho) listed in Table 2 show that SHS in general correlated rather highly with the health impairment score, the agreement to the statement "one is helplessly subjected to the heat", and only weakly 
correlated with the subjective health status, which in turn was weakly correlated with the health impairment score. For SHS at home and at work, the respective correlation coefficients are somewhat lower, and there is no significant correlation with the subjective health status.

Regarding sociodemographic and economic characteristics, the respondents mainly differed in their experiencing heat as stress at home, and to a lesser extent for SHS in general, and not at all for SHS at work. Table 3 lists the test results for SHS at home. Male, young (up to 24 years) respondents, and respondents living as single parents or in shared flats reported higher SHS levels at home. Students and trainees reported higher SHS levels than employed respondents (full- and part-time). Conversely, the retired respondents and those aged 65 years and older reported the lowest levels of SHS at home. Similar to SHS at home, the retired also reported lower SHS in general than the rest of the sample $\left(\chi^{2}(4, n=319)=11.293, p=0.046\right.$; KruskalWallis test).

Only 5 out of the 12 coping measures listed in the questionnaire showed significant differences in SHS (Table 4). Seeking cooler places, allowing oneself to rest, and using the air conditioning were more often associated with lower SHS at work. In comparison to this, the other significant differences point in the opposite direction: avoiding the sun was more often associated with higher SHS levels in all three contexts, using the air conditioning with higher SHS levels in general and at home, and using the fan with higher SHS levels at home.

The respondents differed significantly in their SHS at home for almost all elements of the residential building and the surrounding urban environment included in the questionnaire, but not for SHS in general or at work. The test results for SHS at home in Table 5 show that higher heat loadings of the residential district are associated with higher SHS. Respondents with a one- or two-family home and respondents who have the possibility to use multiple floors in their home reported lower SHS levels than those living in multiple-unit dwellings or in apartment towers. Respondents in apartments in the upper levels and in particular in attics expressed higher SHS at home than those living at ground level. Based on the median values listed in Table 5, however, a steadily increasing average value of SHS with increasing building level was not observed.

Regarding the scores for heat-protective elements, the possibilities to sit outside, and the known insulation elements, the results in Table 5 show that having no or a low number of elements in each case is associated with higher levels of SHS experienced at home; hereby, the respondents who do not have any heat-protective elements (neither shutters nor blinds mounted outside to shade the window, nor air conditioning) disproportionately often lived in apartments in the attic $\left(\chi^{2}\right.$ $(12, n=308)=25.50, p=0.012)$. Only for the walking distance to the next public green space, could no significant difference in the level of SHS at home be observed.

\subsection{Determinants of subjective heat stress}

Table 6 lists the results of the multiple regression analyses to identify which of the variables making a difference at the bivariate level are the main statistic determinants for SHS in general, SHS at home, and SHS at work on a multivariate level of analysis. With resulting determination coefficients $R_{\text {corr }}^{2}$ of 0.567 for SHS in general, 0.458 for SHS at home, and 0.379 for SHS at work, the regression models yielded moderate, yet satisfactory results in terms of the variance explained.

As it can be seen from the standardized beta coefficients in Table 6, first, not all of the variables that yielded significant differences in bivariate analyses turned out to also have a significant effect in the multiple regressions. Second, health impairments and the feeling of being helplessly exposed to the heat had a significant positive (increasing) effect for all three SHS variables. The other determinants varied for SHS in general, at home, and at work. A number of characteristics of the residence significantly influenced the SHS at home only. Both the heat loading of the district and the level used in the building had an effect, whereby living in districts with higher heat loading or living on a higher level in a building increased SHS at home. The possibility to use more than one level at home, a higher number of available heat protection elements, a higher number of possibilities to sit outside, and a higher number of known insulation elements showed a decreasing effect on SHS at home.

Among the coping measures, seeking cooler places and using air conditioning had a significant negative, thus decreasing, effect on SHS at work. In comparison to this and as already observed on the bivariate analysis level, avoiding the sun had a weak positive, thus increasing effect for the SHS in general, and using a fan had a positive effect for SHS at home. The tested demographic variables, age and gender, did not show significant effects in the models, as was the case for the subjective health status.

\section{Discussion}

The presented results of the Karlsruhe questionnaire survey show that the SHS experienced by the 323 respondents in the preceding heat waves was rather high on average. SHS varied for different contexts in daily life. At the same time, SHS is ubiquitous in daily life, at home during day or at night while sleeping, at work, and during other typical daily activities such as being on one's way or during household activities. The health impairments from the heat and the feeling of being helplessly exposed to the heat explain the inter-individual variance in SHS in general, at home, and at work to a satisfactory extent. Characteristics of the residential building and its surroundings only determine the level of SHS experienced at home. Coping measures tantamount to a cooler environment determine SHS at work. The coping measures showed 
Table 2. Correlations (Spearman's rho) for subjective heat stress.

\begin{tabular}{llllllll}
\hline Spearman's rho $(n)$ & \multicolumn{2}{c}{$(1)$} & & & $(3)$ \\
\hline Subjective heat stress & & & & & & \\
(1) ... in general & - & & & & & \\
(2) ... at home & $0.500^{* * *}$ & $(313)$ & - & & & \\
(3) ... at work & $0.570^{* * *}$ & $(254)$ & $0.245^{* * *}$ & $(250)$ & - & \\
Health impairment (score) & $0.637^{* * *}$ & $(308)$ & $0.357^{* * *}$ & $(305)$ & $0.456^{* * *}$ & $(253)$ \\
Subjective health status & $0.134^{*}$ & $(318)$ & $-0.066, \mathrm{~ns}$ & $(316)$ & $0.009, \mathrm{~ns}$ & $(255)$ \\
Negative coping attitude & $0.658^{* * *}$ & $(316)$ & $0.466^{* * *}$ & $(313)$ & $0.533^{* * *}$ & $(252)$ \\
\hline
\end{tabular}

Heat stress in general, at home, and at work is measured on a scale from 1 (not at all) to 9 (very strong). The negative coping attitude was measured with the agreement to the statement "one is helplessly subjected to the heat" on a scale from 1 (no agreement at all) to 5 (strong agreement). ns denotes correlations that are not significant; ${ }^{*} p<0.05,{ }^{* * *} p<0.005$.

Table 3. Differences in subjective heat stress at home by sociodemographic variables.

\begin{tabular}{llrcc}
\hline Variable & Category & $n$ & Median & Test statistics \\
\hline \multirow{2}{*}{ Gender } & female & 156 & 5 & $Z=2.679^{* *}$ \\
& male & 155 & 6 & \\
& up to 24 years & 72 & 7 & $\chi^{2}=35.731^{* * *}$ \\
& 25-34 years & 65 & 6 & \\
35-49 years & 58 & 6 & \\
Living conditions & $50-64$ years & 5 & \\
& 65 years and older & 61 & 4 & \\
& with partner and children & 44 & 4 & $\chi^{2}=20.818^{* * *}$ \\
& with partner & 108 & 5 & \\
& single parent & 10 & 7 & \\
& alone & 86 & 6 & \\
& flat share & 62 & 7 & \\
& assisted living communities & 3 & 3 & \multirow{2}{*}{ Occupational status } \\
& not economically active & 4 & 7 & $\chi^{2}=41.987^{* * *}$ \\
& student/trainee & 77 & 7 & \\
& retired & 61 & 4 & \\
& unemployed & 1 & 7 & \\
& part-time employed $(<70 \%)$ & 30 & 4 & \\
& full-time employed $(>70 \%)$ & 143 & 6 &
\end{tabular}

Heat stress measured on a scale from 1 (not at all) to 9 (very strong). Test statistics: chi-square values obtained in Kruskal-Wallis tests for three or more independent samples; $Z$ values obtained in Mann-Whitney $U$ test for two independent samples. ${ }^{* *} p<0.01$. *** $p<0.005$.

no uniform effect for the SHS. At the same time, the implementation rate of coping behavior among the respondents was remarkably high.

Like other German social science studies, the results of our study underpin that SHS is an issue not solely prevalent at home or at work but throughout everyday life. Similar to the explorative survey conducted during a heat wave in Leipzig in 2010 (Großmann et al., 2012), the average SHS of the Karlsruhe respondents was rather high, in particular compared to the studies by Pfaffenbach and Siuda (2010) in Aachen and by Wittenberg et al. (2012) in Nuremberg. As Pfaffenbach and Siuda (2010) carried out their study in late spring 2010 and Wittenberg et al. (2012) in summer 2011 without particularly hot temperatures, the higher aver- age value of SHS in the Karlsruhe survey can be explained by the immediate heat experience prior to the survey.

The health impairments suffered during the heat waves emerged as one of the major determinants for SHS in general, at home, and at work. Conversely, the self-assessed subjective health status did not significantly determine SHS, even though respondents with a lower subjective general health status reported to be suffering more often from health impairments. Similar to our results, Pfaffenbach and Siuda (2010) observed higher SHS rates among those with respiratory and chronic cardiovascular diseases. The results of our study also correspond with the results of epidemiologic studies showing higher mortality or hospital admission rates during heat waves among those with pre-existing diseases (Conti et al., 2007; D'Ippoliti et al., 2010; Fouillet et al., 2006; Scherber 
Table 4. Differences in subjective heat stress by implemented measures.

\begin{tabular}{|c|c|c|c|c|c|c|c|c|c|}
\hline \multirow[t]{2}{*}{ Measure } & \multicolumn{3}{|c|}{ Heat stress in general } & \multicolumn{3}{|c|}{ Heat stress at home } & \multicolumn{3}{|c|}{ Heat stress at work } \\
\hline & $n$ & $M$ & $Z$ & $n$ & $M$ & $Z$ & $n$ & $M$ & $Z$ \\
\hline Avoid sun & & & $-3.865^{* * *}$ & & & $-2.082^{*}$ & & & $2.274^{*}$ \\
\hline not implemented & 46 & 4 & & 46 & 5 & & 41 & 6 & \\
\hline implemented & 272 & 7 & & 269 & 6 & & 214 & 7 & \\
\hline Seek cooler places & & & $-1.845, \mathrm{~ns}$ & & & $-1.910, \mathrm{~ns}$ & & & $-4.494^{*}$ \\
\hline not implemented & 160 & 7 & & 159 & 6 & & 147 & 7 & \\
\hline implemented & 150 & 6 & & 149 & 5 & & 107 & 6 & \\
\hline Slow down, allow oneself rest & & & $-0.591, \mathrm{~ns}$ & & & $-1.435, \mathrm{~ns}$ & & & $2.042^{*}$ \\
\hline not implemented & 148 & 7 & & 148 & 6 & & 143 & 7 & \\
\hline implemented & 170 & 7 & & 167 & 5 & & 112 & 6 & \\
\hline Air conditioning & & & $-2.092^{*}$ & & & $-2.773^{* *}$ & & & $-2.388^{*}$ \\
\hline not implemented & 274 & 6 & & 272 & 6 & & 225 & 7 & \\
\hline implemented & 30 & 7 & & 29 & 7 & & 28 & 5 & \\
\hline Use of fan & & & $-1.730, \mathrm{~ns}$ & & & $-2.470 *$ & & & $-1.556, \mathrm{~ns}$ \\
\hline not implemented & 169 & 7 & & 168 & 5 & & 129 & 7 & \\
\hline implemented & 141 & 7 & & 140 & 6 & & 126 & 7 & \\
\hline
\end{tabular}

$M$ denotes median; $Z$ values obtained in Mann-Whitney $U$ test for two independent samples; ns denotes test results that are not significant ${ }^{*} p<0.05$. ${ }^{* *} p<0.01$. *** $p<0.005$.

et al., 2014; Vandentorren et al., 2006). Furthermore, because of the everyday life approach of our study, the specific health symptoms experienced during heat listed in the questionnaire and consequently included in our health impairments score did not follow the terminology of the International Statistical Classification of Diseases (ICD) as used in epidemiological studies. Like in previous social science research (Großmann et al., 2012) the presented results underline how even less serious health impairments that may not represent the beginning of a lethal chain during heat, such as sweating, feeling tired, sleep disorders, and concentration problems determine SHS of citizens with a predominantly good or very good subjective health status. In this respect, the results of our experience-based study of SHS in daily life measured with subjective judgements complement the evidence from epidemiologic mortality and morbidity studies.

The attitude towards heat as a problem one is helplessly subject to turned out to be the second major determinant of SHS at home, in general, and at work; hereby, the negative coping attitude among the Karlsruhe respondents is in the same range as observed by Wittenberg et al. (2012) in Nuremberg. Nevertheless, they actually implemented more measures to cope with the heat than found in other studies in Germany and the US (Pfaffenbach and Siuda, 2010; Sampson et al., 2013; Sheridan, 2007). The feeling of being helplessly exposed to the heat is reflected also in the reported coping behavior, as many respondents did not have the possibility to implement the measures they would actually have liked to implement: air conditioning, seeking cooler places, shifting activities to other times of the day, slowing down, and avoiding exertion; all these represent ways to either escape from the heat or to change or reduce activities to better sustain the heat.
The residential building and the urban environment only turned out to be determinants for SHS at home. The elements influencing SHS, namely the location of the level within a building, heat protection elements, thermal insulation, and outdoor recreation possibilities, and the residential district's heat loading category, confirm results of previous surveys in German cities (Großmann et al., 2012; Pfaffenbach and Siuda, 2010). Moreover, they are in line with results obtained in temperature-related indoor and outdoor heat discomfort studies regarding the location of the level within the building (Langner et al., 2014; White-Newsome et al., 2012). The decreasing effect elements of heat protection, outdoor recreation, and thermal insulation have on the SHS at home clearly illustrates at the same time that such structural measures are felt by building inhabitants during heat waves. Unlike studies that demonstrate the proportion of green space in the residential area (Lafortezza et al., 2009; Xu et al., 2013), in the Karlsruhe survey no difference was observed in the SHS stress for the walking distance to the next public garden. Empirical research in Leipzig similarly showed only a slight relationship of perceived heat at home with green space (Franck et al., 2013) and indicated that green space contributed rather to the general SHS than to the SHS at home (Großmann et al., 2012). In our study, having a garden was one element of the score of the outdoor recreation elements that has a significant decreasing effect on subjective heat stress. Therefore, our findings underpin implicitly the role of green space as a decreasing factor for SHS at home that - in contrast to public gardens within walking distance - is directly accessible from home.

At the same time, the elements of buildings and the urban environment influencing SHS in our study refer to individual buildings' architecture, various building materials, 
Table 5. Subjective heat stress at home by structural building elements and urban environment.

\begin{tabular}{|c|c|c|c|c|}
\hline Element & Category & $n$ & Median & Test statistics \\
\hline \multirow[t]{4}{*}{ Heat loading of residential district } & category 1 (lowest) & 44 & 4 & \multirow{4}{*}{$\chi 2=26.248^{* * *}$} \\
\hline & category 2 & 130 & 5 & \\
\hline & category 3 & 116 & 7 & \\
\hline & category 4 (highest) & 27 & 7 & \\
\hline \multirow[t]{3}{*}{ House type } & one or two-family home & 50 & 4 & \multirow[t]{3}{*}{$\chi 2=25.095^{* * *}$} \\
\hline & multiple dwelling unit & 239 & 6 & \\
\hline & apartment tower & 24 & 7 & \\
\hline \multirow[t]{2}{*}{ Multiple levels } & lives on one level & 286 & 6 & \multirow{2}{*}{$Z=-4.689^{* * *}$} \\
\hline & lives on multiple levels & 31 & 3 & \\
\hline \multirow[t]{5}{*}{ Level $^{\mathrm{a}}$} & ground level & 61 & 5 & \multirow[t]{5}{*}{$\chi 2=28.603^{* * *}$} \\
\hline & lower levels & 54 & 6 & \\
\hline & middle levels & 48 & 4 & \\
\hline & upper levels & 57 & 7 & \\
\hline & attic & 66 & 8 & \\
\hline \multirow[t]{4}{*}{ Heat-protective elements on building (score) } & 0 elements & 28 & 8 & \multirow[t]{4}{*}{$\chi 2=23.265^{* * *}$} \\
\hline & 1 element & 185 & 6 & \\
\hline & 2 elements & 84 & 5 & \\
\hline & 3 elements & 6 & 4 & \\
\hline \multirow[t]{4}{*}{ Possibilities at home to be outside (score) } & 0 elements & 53 & 7 & \multirow[t]{4}{*}{$\chi 2=35.571^{* * *}$} \\
\hline & 1 element & 104 & 7 & \\
\hline & 2 elements & 99 & 5 & \\
\hline & 3 elements & 45 & 4 & \\
\hline \multirow[t]{7}{*}{ Known insulation elements (score) } & 0 elements & 78 & 7 & \multirow[t]{7}{*}{$\chi 2=36.165^{* * *}$} \\
\hline & 1 element & 67 & 6 & \\
\hline & 2 elements & 49 & 6 & \\
\hline & 3 elements & 46 & 6 & \\
\hline & 4 elements & 31 & 4 & \\
\hline & 5 elements & 27 & 5 & \\
\hline & 6 elements & 19 & 4 & \\
\hline Walking distance to next public garden & $\begin{array}{l}1 \text { to } 5 \mathrm{~min} \\
>5 \mathrm{~min}\end{array}$ & $\begin{array}{l}164 \\
130\end{array}$ & $\begin{array}{l}6 \\
6\end{array}$ & $Z=-1.547, \mathrm{~ns}$ \\
\hline
\end{tabular}

Test statistics: chi-square values obtained in Kruskal-Wallis tests for three or more independent samples; $Z$ values obtained in

Mann-Whitney $U$ test for two independent samples. ${ }^{a}$ Without respondents living on multiple levels. ns denotes test results that are not significant. ${ }^{* * *} p<0.005$.

urban structures, and characteristics in the urban environment that contribute to the small-scale variability also known from studies of indoor temperature distribution (Franck et al., 2013, Langner et al., 2014; White-Newsome et al., 2012). To control and isolate all influencing factors and to achieve generalizable results from case studies, studies of SHS as well as studies that compare temperature measurements with subjective perceived temperature (Franck et al., 2013, Maras et al., 2014) would require very large samples, uniform study concepts, and similar weather conditions to achieve comparable and statistically significant results. Given the size of our sample, our approach to capture the effects of single building elements and characteristics in scores for heat protection, thermal insulation, and outdoor recreation elements yielded reasonable results.
In contrast to the expectation from the overwhelming findings of mortality studies and the findings by Pfaffenbach and Siuda (2010), age did not turn out to be a significant determinant for SHS in the Karlsruhe study. Rather on the contrary, elderly respondents reported lower SHS at home and in general than younger respondents. Großmann et al. (2012) observed similarly surprising lower SHS levels of elderly persons. They attributed this to the effect that elderly, retired persons were able to apply more measures that change daily routines due to freedom from work constraints and consequently higher coping capacities. While a higher implementation rate of such measures by the elderly and retired compared to the economic active ones was also found among the Karlsruhe respondents, there are more aspects in the data to explain the lower SHS of the elderly. First, the elderly more 
Table 6. Determinants of subjective heat stress (multiple regression).

\begin{tabular}{|c|c|c|c|}
\hline $\begin{array}{l}\text { Dependent variable } \\
\text { Model summary }\end{array}$ & $\begin{array}{l}\text { Subjective heat stress in general } \\
R^{2}=0.769, R_{\text {corr }}^{2}=0.568 \\
F(16.279)=5.262, p<0.000\end{array}$ & $\begin{array}{l}\text { Subjective heat stress at home } \\
R^{2}=0.699, R_{\text {corr }}^{2}=0.459 \\
F(16.279)=16.641, p<0.000\end{array}$ & $\begin{array}{l}\text { Subjective heat stress at work } \\
R^{2}=0.651, R_{\text {corr }}^{2}=0.383 \\
F(16.230)=10.560, p<0.000\end{array}$ \\
\hline Independent variables $^{\mathrm{a}}$ & $\beta$ & $\beta$ & $\beta$ \\
\hline (Constant) & - & - & - \\
\hline Health impairments from heat & $0.408^{* * *}$ & $0.241^{* * *}$ & $0.295^{* * *}$ \\
\hline Health status & ns & ns & ns \\
\hline Belief: "feel helplessly subjected to heat" & $0.412^{* * *}$ & $0.244^{* * *}$ & $0.354^{* * *}$ \\
\hline Avoid direct sun & $0.128^{* * *}$ & ns & ns \\
\hline Seek cooler places & ns & ns & $-0.151^{* *}$ \\
\hline Allow oneself to rest & ns & $\mathrm{ns}$ & ns \\
\hline Use air conditioning & $\mathrm{ns}$ & $\mathrm{ns}$ & $-0.138^{*}$ \\
\hline Use a fan & $\mathrm{ns}$ & $0.104^{*}$ & ns \\
\hline Heat loading category of residential district (1-4) & ns & $0.122^{* *}$ & $\mathrm{~ns}$ \\
\hline Resides on more than one level & ns & $-0.097 *$ & ns \\
\hline Level category & $\mathrm{ns}$ & $0.155^{* * *}$ & ns \\
\hline Heat protection elements score & $\mathrm{ns}$ & $-0.098^{*}$ & ns \\
\hline Possibilities sitting outside score & ns & $-0.141^{* * *}$ & ns \\
\hline Thermal insulation elements score & ns & $-0.135^{* * *}$ & ns \\
\hline Age (classes) & ns & ns & ns \\
\hline Gender (male) & ns & $\mathrm{ns}$ & ns \\
\hline
\end{tabular}

${ }^{\mathrm{a}}$ Regression method: enter. $\beta$ denotes standardized regression coefficient. ns denotes coefficients that are not significant. ${ }^{*} p<0.05 .{ }^{* *} p<0.01 .{ }^{* * *} p<0.005$.

often lived in districts with a lower heat loading and in single family homes which were also associated with lower SHS levels. These findings can therefore be attributed to a sociospatial effect in the sample. In their spatial analysis of heatrelated hospital admissions due to respiratory diseases in the city of Berlin, Scherber et al. (2014) similarly observed that the elderly more often lived in areas outside the city center with lower population density and with lower heat loadings. Second, the elderly in the sample were either involved in the survey through the distribution of the paper and pencil questionnaire among the network of senior groups of the senior citizens' office of the city of Karlsruhe or they participated in the online survey. They therefore represent elderly persons who are active, take part in social activities, and are in reach of social services. The frail, bedridden elderly persons who are most susceptible to heat were not reached. This is, admittedly, a general problem of questionnaire studies (Bassil and Cole, 2010; Klinenberg, 2002). Furthermore, studies have shown that the elderly's perception of their own vulnerability to heat due to age often does not correspond to their higher health risk during heat (Abrahamson et al., 2009; Wolf et al., 2010). In physiological terms, ageing is associated with intrinsic changes in the thermoregulation and with impaired homeostasis with the result that elderly persons may not be aware of getting ill from high temperatures; additionally, the use of medicines may interfere with the thermoregulation of the body (Basu and Samet, 2002; Gronlund, 2014; Koppe et al., 2004). In this regard, the result of lower SHS reported by the elderly in the sample is no contradiction. In addition to the socio-spatial and the self-selection effects in the sample, the lower SHS of elderly as found in the Karlsruhe study therefore could be attributed to a combination of changes in the effects of thermoregulation, and active coping behavior with changing daily routines more often than economically active persons.

The observed coping behavior of all respondents confirms the pattern also found in other studies (Großmann et al., 2012; Sheridan, 2007; Sheridan and Kalkstein, 2007). Simple behavior measures and available structural measures to keep the indoor temperature at a tolerable level were used more often than measures that change daily routines. Despite the high implementation rate of measures to cope actively with the heat, no clear and uniform effect of the coping behavior on SHS was found. The results of our study suggest two reasons for this. First, the very high implementation rate of simple measures, such as drinking more fluids, resulted in very different sizes of subgroups, which implicitly limits the possibility of analyzing their effects. Thus, even if we were not able to observe significant differences in SHS levels related to the measure of drinking more fluids or airing and shading the rooms, it cannot be concluded from the results of the study that these measures do not make a difference to SHS at all. Second, both on a bivariate and multivariate analysis level, the implementation of some measures, namely to avoid direct sun and to use a fan, was associated with higher SHS at home. The chicken-and-egg question underlying this result i.e., the question whether the observed differences are an effect of the measure or whether implementing a measure is a result of high SHS and thus an indicator of higher SHS, cannot be answered based on the presented study. These open questions, however, underline that further research on the effects of coping behavior is necessary to understand how different types of coping measures help reduce SHS and the feeling of being helplessly subject to the heat. This is in par- 
ticular the case as the results of the study also show that coping behavior during heat is performed within the daily (working) life, which poses constraints, limits, or opportunities - as can be seen in the case of the retired respondents - to implement certain measures.

The above has already indicated limitations of the study due to the composition and effects in the sample. As already mentioned in Sect. 3.3, the analysis of further variables for SHS at work e.g., type of work and work environment, was limited and could not be included in the further investigation. Therefore, in particular the results on SHS at work have only limited statistical power and need further exploration and confirmation from future studies. This is particularly important as SHS at work was higher than SHS at home.

Additionally, the survey was only in the German language, which limited the participation of non-German-speaking residents in Karlsruhe. Regarding particular social groups to reach with the random sample of the survey, the priority of our survey immediately after the heat waves was to reach elderly people with the additional paper version of the questionnaire; hereby, the differences in subjective heat stress of elderly citizens as presented in the paper cannot be related to the form of the questionnaire. Nonparametric statistic tests carried out before had shown no differences in SHS for the online/printed version of the questionnaire among the survey participants older than 65 years.

As a case study from Karlsruhe the generalizability to subjective heat stress in other heat wave events is limited. However, while the level of heat stress surveyed in the other surveys in Germany differs with or without immediate experience of a heat wave, the factors that make a difference to the self-reported heat stress are very similar. In future studies that transfer our study concept to other German cities and heat waves, we therefore would expect similar results on the major or minor factors determining subjective heat stress during a heat wave, in particular for health impairments as a major determinant in several contexts of daily life and for the factors that help reduce exposure to high temperatures at home or at work.

Although the survey focused on SHS and coping behavior of the respondents in their everyday life, the results still suggest a number of recommendations for adaptation strategies to future heat waves. Given the results that health impairments from heat and the negative coping attitude are the ubiquitous factors of SHS, the results underline the need for prevention of health impairments to reduce the health impacts of heat waves. While high temperatures and heat in summer are normal in common sense, it is particularly important to challenge the belief that nothing can be done to respond to and cope with the heat. Thus, in addition to heat warning systems, accompanying communication of measures to prevent (subjective) heat stress and health impairments is important for learning and for building coping capacities towards future heat waves. Finally, measures to cope with heat are performed by the respondents within the constraints and structures of daily life while they maintain the basic structure of daily routine. Therefore, more research on the social processes and arrangements in current societies that limit or enable long-term adaptation to heat is necessary. This also includes more research on preventing heat stress at work.

\section{Conclusion}

The results of our survey on subjective heat stress (SHS) experienced by urban citizens during heat waves in August 2013 in the city of Karlsruhe, Germany, extend the current understanding of the determining factors of SHS in the context of everyday life. Health impairments experienced during the heat and the feeling of being helplessly exposed to the heat contributed to explaining SHS in general, at home, and at work. Elements of the urban spatial environment and the residential building were factors of SHS at home only. Given the variation of significant determinants of SHS stress in general, at home, and at work, it can be concluded that the individual SHS is context-dependent and that the determinants of SHS differ upon context regarding relevance and type. The results presented confirm and complement results of other social science studies of SHS with an expressed-preferences approach to measuring SHS. In general, they also agree with the main findings of heat stress factors obtained in studies based on measurements of meteorological parameters combined with morbidity and mortality data or with thermoregulation models.

For long-term strategies to reduce heat stress for urban citizens, the results illustrate, on the one hand, how structural measures for heat protection of buildings, energy-efficient refurbishment of buildings, and urban planning measures that focus on green space and well-being in the city can help reduce subjective heat stress in residential buildings during heat waves. To develop socially appropriate adaptations that help reduce heat stress, the results, on the other hand, show that responses to heat are performed within the scope and constraints of action in daily private and professional life. Therefore, further research is needed to understand how various processes of daily social (working) life enable or limit individual coping and how this may be fed into adaptation strategies.

Author contributions. Tina Kunz-Plapp is the main author of the study. Julia Hackenbruch and Janus Willem Schipper helped with the data collection and contributed to the writing of the manuscript, in particular with regards to the meteorological and climate context of the study.

Acknowledgements. The research activities for the presented study were funded by the Climate Initiative REKLIM (regional climate change) of the Helmholtz Association (Germany). We thank the two 
anonymous reviewers for their constructive comments and suggestions that helped us to improve the quality of the paper. Furthermore we would like to thank the editorial team, in particular Kai Schröter, for their fast and supportive handling of the review process.

We acknowledge support by the Deutsche Forschungsgemeinschaft and Open Access Publishing Fund of Karlsruhe Institute of Technology.

The article processing charges for this open-access publication were covered by a Research

Centre of the Helmholtz Association.

Edited by: K. Schröter

Reviewed by: two anonymous referees

\section{References}

Abrahamson, V., Wolf, J., Lorenzoni, I., Fenn, B., Kovats, S., Wilkinson, P., Adger, W. N., and Raine, R.: Perceptions of heatwave risks to health: interview-based study of older people in London and Norwich, UK, J. Public Health (Oxf.), 31, 119-126, doi:10.1093/pubmed/fdn102, 2009.

Bach, C., Birkmann, J., Kropp, J., Olonschek, M., Setiadi, N., Vollmer, M., and Walter, C.: Abschätzung der Verwundbarkeit gegenüber Hitzewellen und Starkregen, Praxis im Bevölkerungsschutz, Band 11, Auflage 09/2013, Bundesamt für Bevölkerungsschutz und Katastrophenhilfe (BBK), Bonn, Germany, http://www.bbk.bund.de/SharedDocs/Downloads/ BBK/DE/Publikationen/Praxis_Bevoelkerungsschutz/ Band_11_PraxisBS_Hitzewellen-Starkregen.pdf;jsessionid= 199B822A577456D2630E993DAF4770CE.1_cid345?_blob= _publicationFile (last access: 31 March 2016), 172 pp., 2013.

Bassil, K. L. and Cole, D. C.: Effectiveness of public health interventions in reducing morbidity and mortality during heat episodes: a structured review, Int. J. Env. Res. Public Health, 7, 991-1001, doi:10.3390/ijerph7030991, 2010.

Basu, R. and Samet, J. M.: An exposure assessment study of ambient heat exposure in an elderly population in Baltimore, Maryland, Environ. Health. Persp., 110, 1219-1224, 2002.

Beniston, M., Stephenson, D. B., Christensen, O. B., Ferro, C. A., Frei, C., Goyette, S., Halsnaes, K., Holt, T., Jylhä, K., Koffi, B., Palutikof, J., Schöll, R., Semmler, T., and Woth, K.: Future extreme events in European climate: an exploration of regional climate model projections, Climatic Change, 81, 71-95, doi:10.1007/s10584-006-9226-z, 2007.

Birkmann, J., Cardona, O. D., Carreño, M. L., Barbat, A. H., Pelling, M., Schneiderbauer, S., Kienberger, S., Keiler, M., Alexander, D., Zeil, P., and Welle, T.: Framing vulnerability, risk and societal responses: the MOVE framework, Nat. Hazards, 67, 193-211, doi:10.1007/s11069-013-0558-5, 2013.

Blazejczyk, K., Epstein, Y., Jendritzky, G., Staiger, H., and Tinz, B.: Comparison of UTCI to selected thermal indices, Int. J. Biometeorol., 56, 515-535, doi:10.1007/s00484-011-0453-2, 2012.

Borell, C., Marí-Dell'Olmo, M., Rodíguez-Sanz, M., Garcia-Olalla, P., Caylá, J. A., Benach, J., and Muntaner, C.: Socioeconomic position and excess mortality during the heat wave of 2003 in Barcelona, European J. Epidemiol., 21, 633-640, doi:10.1007/s10654-006-9047-4, 2006.
Burke, M., Hsiang, S. M., and Miguel, E: Global Non-Linear Effect of Temperature on Economic Production, Nature, 527, 235-239, doi:10.1038/nature15725, 2015.

Conti, S., Masocco, M., Meli, P., Minelli, G., Palummeri, E., Solimini, R., Toccaceli, V., and Vichi, M.: General and specific mortality among the elderly during the heat wave in Genova (Italy), Environ. Res., 103, 267-274, doi:10.1016/j.envres.2006.06.003, 2007.

D’Ippoliti, D., Michelozzi, P., Marino, C., de'Donato, F., Menne, B., Katsouyanni, K., Kirchmayer, U., Analitis, A., MedinaRamón, M., Paldy, A., Atkinson, A., Kovats, S., Bisanti, L., Schneider, A., Lefranc, A., Iñiguez, C., and Perucci, C. A.: The impact of heat waves on mortality in 9 European cities: results from the EuroHEAT project, Environ. Health, 9, 37, doi:10.1186/1476-069X-9-37, 2010.

Dunne, J. P., Stouffer, R. J., and John, J. G.: Reductions in labour capacity from heat stress under climate warming, Nature Climate Change, 3, 563-566, doi:10.1038/nclimate1827, 2013.

EEA (European Environment Agency): Urban adaptation to climate change in Europe. Challenges and opportunities for cities together with supportive national and European policies, European Environment Agency Report No. 2/2012, European Environment Agency, Copenhagen, 148 pp., doi:10.2800/41895, 2012.

Fernandez Milan, B. and Creutzig, F.: Reducing urban heat wave risk in the 21st century, Current Opinion in Environmental Sustainability, 14, 221-231, doi:10.1016/j.cosust.2015.08.002, 2015.

Fischer, E. M. and Schär, C.: Consistent geographical patterns of changes in high-impact European heat waves, Nat. Geosci., 3, 398-403, doi:10.1038/NGEO866, 2010.

Fouillet, A. Rey, G., Laurent, F., Pavillon, G., Bellec, S., Guihenneuc-Jouyaux, C., Clavel, J., Jougla, E., and Hémon, D.: Excess mortality related to the August 2003 heat wave in France, Int. Arch. Occ. Env. Hea., 80, 16-24, doi:10.1007/s00420-0060089-4, 2006.

Franck, U., Krüger, M., Schwarz, N., Grossmann, K., Röder, S., and Schlink, U.: Heat stress in urban areas: Indoor and outdoor temperatures in different urban structure types and subjectively reported well-being during a heat wave in the city of Leipzig, Meteorol. Z., 22, 167-177, doi:10.1127/0941-2948/2013/0384, 2013.

Gabriel, K. M. and Endlicher, W. R.: Urban and rural mortality rates during heat waves in Berlin and Brandenburg, Germany, Environ. Pollut., 159, 2044-2050, doi:10.1016/j.envpol.2011.01.016, 2011.

German Weather Service: Climate Data for Germany, ftp://ftp-cdc. dwd.de/pub/CDC/observations_germany/climate/ (last access: 31 March 2016), 2014.

Ginski, S., Klemme, M., Pfaffenbach, C., and Siuda, A.: Anpassung durch Akzeptanz - Der Umgang lokaler Akteure mit sommerlicher Hitze, english Title: Adjustment through Acceptance - The Approach of Local Actors to Summer Heat Waves, disP - The Planning Review, 49, 86-100, doi:10.1080/02513625.2013.827514, 2013.

Grize, L., Huss, A., Thommen, O., Schindler, C., and BraunFahrländer, C.: Heat wave 2003 and mortality in Switzerland, Swiss Med. Wkly., 135, 200-205, 2005.

Gronlund, C. J.: Racial and Socioeconomic Disparities in HeatRelated Health Effects and Their Mechanisms: A Review, Cur- 
rent Epidemiology Reports, 1, 165-73, doi:10.1007/s40471-0140014-4, 2014

Großmann, K., Franck, U., Krüger, M., Schlink, U., Schwarz, N., and Stark, K.: Soziale Dimensionen von Hitzebelastung in Grossstädten (english title: Social dimensions of heatstress in cities), disP - The Planning Review, 48, 56-68, doi:10.1080/02513625.2012.776818, 2012.

Hansen, A., Bi, P., Nitschke, M., Pisaniello, D., Newbury, J., and Kitson, A.: Perceptions of heat-susceptibility in older persons: Barriers to adaptation, Int. J. Env. Res. Public Health, 8, 47144728, doi:10.3390/ijerph8124714, 2011.

Harlan, S. L., Brazel, A. J., Prashad, L., Stefanov, W. L., and Larsen, L.: Neighborhood microclimates and vulnerability to heat stress, Soc. Sci. Med., 63, 2847-2863, doi:10.1016/j.socscimed.2006.07.030, 2006.

IPCC (Intergovernmental Panel on Climate Change): Climate Change 2013: The Physical Science Basis. Contribution of Working Group I to the Fifth Assessment Report of the Intergovernmental Panel on Climate Change, edited by: Stocker, T. F., Qin, D., Plattner, G.-K., Tignor, M., Allen, S. K., Boschung, J., Nauels, A., Xia, Y., Bex, V., and Midgley, P. M., Cambridge University Press, Cambridge, United Kingdom and New York, NY, USA, 1535 pp., doi:10.1017/CBO9781107415324, 2013.

Jendritzky, G., de Dear, R., and Havenith, G.: UTCI - Why another thermal index?, Int. J. Biometeorol., 56, 421-428, doi:10.1007/s00484-011-0513-7, 2012.

Kalkstein, A. J. and Sheridan, S. C.: The social impacts of the heathealth watch/warning system in Phoenix, Arizona: assessing the perceived risk and response of the public, Int. J. Biometeorol., 52, 43-55, doi:10.1007/s00484-006-0073-4, 2007.

Klinenberg, E.: Heat Wave. A social autopsy of disaster in Chicago, The University of Chigago Press, Chicago, 305 pp., 2002.

Koppe, C., Kovats, S. R., Menne, B., and Jendritzky, G.: Heatwaves: risks and responses, Health and Global Environmental Change Series No. 2, WHO Regional Office for Europe, Copenhagen, http://www.euro.who.int/_data/assets/pdf_ file/0008/96965/E82629.pdf (last access: 31 March 2016), 124 pp., 2004.

Laaidi, K., Zeghnoun, A., Dousset, B., Bretin, P., Vandentorren, S., Giraudet, E., and Beaudeau, P.: The impact of heat islands on mortality in Paris during the August 2003 heat wave, Environ. Health Persp., 120, 254-259, doi:10.1289/ehp.1103532, 2012.

Lafortezza, R., Carrus, G., Sanesi, G., and Davies, C.: Benefits and well-being perceived by people visiting green spaces in periods of heat stress, Urban For. Urban Gree., 8, 97-108, doi:10.1016/j.ufug.2009.02.003, 2009.

Langner, M., Scherber, K., and Endlicher, W. R.: Indoor heat stress: An assessment of human bioclimate using the UTCI in different buildings in Berlin, Erde, 144, 260-273, doi:10.12854/erde-14418, 2014.

Laschewski, G. and Jendritzky, G.: Effects of the thermal environment on human health: an investigation of 30 years of daily mortality from SW Germany, Clim. Res., 21, 91-103, 2002.

Lissner, T. K., Holsten, A., Walther, C., and Kropp, J. P.: Towards sectoral and standardised vulnerability assessments: the example of heatwave impacts on human health, Climatic Change, 112, 687-708, doi:10.1007/s10584-011-0231-5, 2012.

Madrigano, J., Mittleman, M. A., Baccarelli, A., Goldberg, R., Melly, S., von Klot, S., and Schwartz, J.: Temperature, Myocar- dial Infarction, and Mortality: Effect Modification by Individual and Area-Level Characteristics, Epidemiology, 24, 439-446, doi:10.1097/EDE.0b013e3182878397, 2013.

Maras, I., Buttstädt, M., Hahmann, J., Hofmeister, H., and Schneider, C.: Investigating public places and impacts of heat stress in the city of Aachen, Germany, Erde, 144, 290-303, doi:10.12854/erde-144-20, 2014

Mühr, B.: Klimadiagramme weltweit, www.klimadiagramme.de (last access: 31 March 2016), 2014.

Nachbarschaftsverband Karlsruhe: ExWoSt-Modellvorhaben Innenentwicklung versus Klimakomfort Nachbarschaftsverband Karlsruhe, http://www.nachbarschaftsverband-karlsruhe. de/b4/exwost/HF_sections/content/ZZkHSr5tGIMDWn/ ZZkNvxspnzilQZ/ExWoSt_NVK_A4_Web.pdf (last access: 31 March 2016), 39 pp., 2013.

Oke, T. R.: City size and the urban heat island, Atmos. Environ., 7, 769-779, 1973.

Patz, J. A., Campbell-Lendrum, D., Holloway, T., and Foley, J. A.: Impact of regional climate change on human health, Nature, 438, 310-317, doi:10.1038/nature04188, 2005.

Pfaffenbach, C. and Siuda, A.: Hitzebelastung und Hitzewahrnehmung im Wohn- und Arbeitsumfeld der Generation 50plus in Aachen, Europa Regional, http://nbn-resolving.de/urn: nbn:de:0168-ssoar-314920 (last access: 31 March 2016), 18, 192-206, 2010.

Revi, A., Satterthwaite, D. E., Aragón-Durand, F., Corfee-Morlot, J., Kiunsi, R. B. R., Pelling, M., Roberts, D. C., and Solecki, W.: Urban areas, in: Climate Change 2014: Impacts, Adaptation, and Vulnerability. Part A: Global and Sectoral Aspects, Contribution of Working Group II to the Fifth Assessment Report of the Intergovernmental Panel on Climate Change, edited by: Field, C. B., Barros, V. R., Dokken, D. J., Mach, K. J., Mastrandrea, M. D., Bilir, T. E., Chatterjee, M., Ebi, K. L., Estrada, Y. O., Genova, R. C., Girma, B., Kissel, E. S., Levy, A. N., MacCracken, S., Mastrandrea, P. R., and White, L. L., Cambridge University Press, Cambridge, United Kingdom and New York, NY, USA, 535-612, 2014.

Revich, B. A. and Shaposhnikov, D. A.: Climate change, heat waves, and cold spells as risk factors for increased mortality in some regions of Russia, Studies on Russian Economic Development, 23, 195-207, doi:10.1134/S1075700712020116, 2012.

Robine, J.-M., Cheung, S. L. K., Le Roya, S., van Oyen, H., Griffiths, C., Michel, J.-P., and Herrmann, F. R.: Death toll exceeded 70,000 in Europe during the summer of 2003, C. R. Biol., 331, 171-178, doi:10.1016/j.crvi.2007.12.001, 2008.

Robinson, P. J.: On the definition of a Heat Wave, J. Appl. Meteorol., 40, 762-775, doi:10.1175/15200450(2001)040<0762:OTDOAH>2.0.CO;2, 2001.

Sampson, N. R., Gronlund, C. J., Buxton, M. A., Catalano, L., White-Newsome, J. L., Conlon, K. C., O’Neill, M. A., McCormick, S., and Parker, E. A.: Staying cool in a changing climate: Reaching vulnerable populations during heat events, Global Environ. Chang., 23, 475-484, doi:10.1016/j.gloenvcha.2012.12.011, 2013.

Scherber, K., Langner, M., and Endlicher, W.: Spatial analysis of hospital admissions for respiratory diseases during summer months in Berlin taking bioclimatic and socio-economic aspects into account, Erde, 144, 217-237, doi:10.12854/erde-144-16, 2014. 
Semenza, J. C., Hall, D. E., Wilson, D. J., Bontempo, B. D., Sailor, D. J., and George, L. A.: Public perception of climate change: voluntary mitigation and barriers to behavior change, Am. J. Prev. Med., 35, 479-487, doi:10.1016/j.amepre.2008.08.020, 2008.

Sheridan, S. C.: A survey of public perception and response to heat warnings across four North American cities: an evaluation of municipal effectiveness, Int. J. Biometeorol., 52, 3-15, doi:10.1007/s00484-006-0052-9, 2007.

Smargiassi, A., Goldberg, M. S., Plante, C., Fournier, M., Baudouin, Y., and Kosatsky, T.: Variation of Daily Warm Season Mortality as a Function of Micro-Urban Heat Islands, J. Epidemiol. Commun. H., 63, 659-664. doi:10.1136/jech.2008.078147, 2009.

Stadt Karlsruhe, Umwelt- und Arbeitsschutz: Anpassung an den Klimawandel, Bestandsaufnahme und Strategie für die Stadt Karlsruhe, http://www.karlsruhe.de/b3/natur_ und_umwelt/klimaschutz/klimafolgen/HF_sections/content/ ZZ133ZxibxWJEn/ZZ1342BXSjoXv9/Bericht_Klimawandel_ web.pdf (last access: 28 May 2015). 2013.

Staiger, H., Laschewski, G., and Grätz, A.: The perceived temperature - a versatile index for the assessment of the human thermal environment. Part A: scientific basics, Int. J. Biometeorol., 56, 165-176, doi:10.1007/s00484-011-0409-6, 2012.

Tinz, B., Freydank, E., and Hupfer, P.: Hitzeepisoden in Deutschland im 20. und 21. Jahrhundert, in: Warnsignal Klima. Gesundheitsrisiken. Gefahren für Pflanzen, Tiere und Menschen, edited by: Lozán, J., Graß1, H., Jendritzky, G., Karbe, L., and Reise, K., Wissenschaftliche Auswertungen, Hamburg, Germany, 141-148, 2008.

Uejio, C. K., Wilhelmi, O. V., Golden, J. S., Mills, D. M., Gulino, S. M., and Samenow, J. P.: Intra-urban societal vulnerability to extreme heat: The role of heat exposure and the built environment, socioeconomics, and neighborhood stability, Health Place, 17, 498-507, doi:10.1016/j.healthplace.2010.12.005, 2011.

Vandentorren, S., Suzan, F., Medina, S., Pascal, M., Maulpoix, A., Cohen, J.-C., and Ledrans, M.: Mortality in 13 French cities during the August 2003 heat wave, Am. J. Public Health, 94, 1518, doi:10.2105/AJPH.94.9.1518, 2004.

Vandentorren, S., Bretin, P., Zeghnoun, A., Mandereau-Bruno, L., Croisier, A., Cochet, C., Ribéron, J., Siberan, I., Declercq, B., and Ledrans, M.: August 2003 heat wave in France: risk factors for death of elderly people living at home, Eur. J. Public Health, 16, 583-591, doi:10.1093/eurpub/ck1063, 2006.
Wagner, S., Berg, P., Schädler, G., and Kunstmann, H.: High resolution regional climate model simulations for Germany: Part II - projected climate changes, Clim. Dynam., 40, 415-427, doi:10.1007/s00382-012-1510-1, 2013.

White-Newsome, J. L., Sánchez, B. N., Parker, E. A., Dvonch, J. T., Zhang, Z., and O'Neill, M. S.: Assessing heat-adaptive behaviors among older, urban-dwelling adults, Maturitas, 70, 85-91, doi:10.1016/j.maturitas.2011.06.015, 2011.

White-Newsome, J. L., Sánchez, B. N., Jolliet, O., Zhang, Z., Parker, E. A., Timothy Dvonch, J., and O'Neill, M. S.: Climate change and health: indoor heat exposure in vulnerable populations, Environ. Res., 112, 20-27, doi:10.1016/j.envres.2011.10.008, 2012.

WHO (World Health Organization) and WMO (World Meteorological Organization): Atlas of health and climate, World Health Organization WHO and World Meteorological Organization WMO, http://www.who.int/globalchange/publications/atlas/ report/en/ (last access: 31 March 2016), 2012.

Wittenberg, R., Seebaß, K., Knecht, A., Adrian, C., Borst, J., Fichtner, U., Gerbig, S., Hennige, T., and Thümler, M.: Klimabetroffenheit in Nürnberg. Ausgewählte Ergebnisse eines Lehrforschungsprojekts 2011/12, Universität ErlangenNürnberg, Nürnberg, Interner Bericht, Berichte des Lehrstuhls für Soziologie und Empirische Sozialforschung, Bd. 20121, http://www.soziologie.wiso.uni-erlangen.de/forschung/ publikationen/Projektberichte/b_12-01.pdf (last access: 31 March 2016), 2012.

Wolf, J., Adger, W. N., Lorenzoni, I., Abrahamson, V., and Raine, R.: Social capital, individual responses to heat waves and climate change adaptation: An empirical study of two UK cities, Global Environ. Chang., 20, 44-52, doi:10.1016/j.gloenvcha.2009.09.004, 2010.

Xu, Y., Dadvand, P., Barrera-Gómez, J., Sartini, C., MaríDell'Olmo, M., Borell, C., Medina-Ramón, M., Sunyer, J., and Basagaña, X: Differences on the effect of heat waves on mortality by sociodemographic and urban landscape characteristics, J. Epidemiol. Commun. H., 67, 519-525, doi:10.1136/jech-2012201899, 2013.

Zanobetti, A., O’Neill, M. S., Gronlund, C. J., and Schwartz, J. D.: Susceptibility to Mortality in Weather Extremes: Effect Modification by Personal and Small-Area Characteristics, Epidemiology, 24, 809-819, doi:10.1097/01.ede.0000434432.06765.91, 2013. 